\title{
An Energy-Efficient Smart Comfort Sensing System Based on the IEEE 1451 Standard for Green Buildings
}

\author{
A. Kumar and G. P. Hancke, Senior Member, IEEE
}

\begin{abstract}
In building automation, comfort is an important aspect, and the real-time measurement of comfort is notoriously complicated. In this article, we have developed a wireless, smart comfort sensing system. The important parameters in designing the prevalent measurement of comfort systems such as portability, power consumption, reliability, and system cost were considered. To achieve the target design goals, the communication module, sensor node, and sink node were developed based on the IEEE1451 standard. Electrochemical and semiconductor sensors were considered for the development of the sensor array, and the results of both technologies were compared. The sensor and sink nodes were implemented using the ATMega88 microcontroller. Microsoft Visual Studio 2013 preview was used to create the graphical user interface (GUI) in

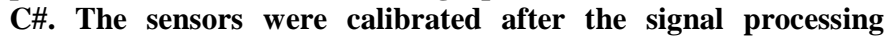
circuit to ensure that the standard accuracy of the sensor was achieved. This article presents detailed design solutions to problems that existed in the literature.
\end{abstract}

Index Terms-IEEE1451 standard, sensor node, thermal comfort, graphical user interface, smart sensor, green building.

\section{INTRODUCTION}

Green building is the term commonly used to define a building equipped with an ambient intelligence system, which can react to predefined conditions in real time [1]. These are context-aware systems in the sense that they can collect data from various sensors embedded in the home environment, extract information, and act accordingly [2]. In addition, a green building is a function of the conservation of natural resources, generation of less waste, comfortable and healthy spaces, and low usage of energy. It also supplements conventional energy needs through nonconventional energy sources. In Heating, Ventilation, and Air Conditioning (HVAC) systems, poorly maintained equipment and dated control systems can yield poor energy performance. The energy efficiency of a building can decrease over time because of deferred equipment maintenance, user habits, improper controls, and much more [3], [4]. These factors could cause an increase in the operating cost. Even worse, modern green buildings can suffer from poor efficiency because of incorrect installation, configuration, and use of increasingly complex building automation and control systems; also, older buildings tend to be less efficient than newer buildings [5], [6]. According to building automation norms, comfort is a major characteristic of a building, other than the usual security and safety.

A. Kumar is at the University of Pretoria, South Africa. (anuj.kumar@up.ac.za)

G.P. Hancke is with the City University of Hong Kong (Hong Kong SAR), and the University of Pretoria. (gp.hancke@ cityu.edu.hk)
Comfort is, to some extent, subjective, and there are many factors that could sway a particular perception of comfort such as acoustical comfort, visual comfort, thermal comfort, and indoor air quality comfort. In this article, we have concentrated on thermal comfort estimation with air quality considerations because thermal comfort and air quality are very significant factors in deciding the human comfort level and building sustainability [7], [8]. According to the American Society of Heating, Refrigerating, and Air-Conditioning Engineers (ASHRAE) 55-2013 and International Organization for Standardization (ISO) 7730, thermal comfort is a "state of mind that expresses satisfaction with the thermal environment". Indoor air (IA) relates the nature of indoor air to the health of building occupants. IA comfort can be affected by varying concentration of gases $\left(\mathrm{CO}\right.$ and $\left.\mathrm{CO}_{2}\right)$ [9]-[13].

Hence, the important goal of our device is to generate a comfortable building climate (cooling, heating, and air quality). Currently, a conservative air conditioning system only senses air temperature and has restrictions in placating inhabitants in the building environment. With the swift growth of processor technologies in this area, there has been a growing demand for comfort measurement and control systems for the best possible intelligent air conditioning system [14]-[22].

In building automation, the real-time measurement of comfort is more complex. Most comfort monitoring systems manually adjust environmental parameters such as light luminosity, temperature, and relative humidity. In recent years, harvesting technology has played an important role in the area of smart sensors. Kang et al. developed an integrated comfort sensing system for indoor climate. They used three measured environmental parameters, that is, temperature, humidity, and air flow. Other parameters such as clothing level, activity level, and mean radiant temperature were considered according to ISO7730 standards [8]. Honeywell et al. developed a TY4700 thermal comfort sensor. They considered the three real-time monitored environmental parameters such as air temperature, radiant temperature, and air velocity. Other parameters such as humidity, clothing level, and activity level were assumed according to ISO7730 standards [12]. Tse et al. developed a measurement system for thermal comfort by using an open network topology. Six smart sensors with networking capability were used to execute practical measurements of the real-time Predicted Mean Vote (PMV) values inside an air-conditioned environment. The smart sensors were linked, which resulted in a network wherein open communication procedures were adopted. They used three kinds of smart sensors, that is, radiation sensors, temperature sensors, and PMV sensors [23], [24]. Kumar et al. 
developed a ZigBee technology-based environment monitoring system for the measurement of indoor and outdoor environments. Based on the developed system, they proposed the procedure of measurement of thermal comfort analysis [25], [47]. Rawi et al. proposed a distributed, fuzzy rule-based wireless sensor network system for calculation of comfort index. The visual comfort, thermal comfort, acoustical comfort, and indoor air comfort factors were also considered [26]. Reffat et al. presented a procedure for estimating the survey-based environmental quality in an office. Arrays such as acoustic comfort, thermal comfort, lighting comfort, and air quality comfort were considered [27]. Atthajariyakul et al. proposed an implemented HVAC control system. They considered only three parameters in the calculation of thermal comfort and indoor air quality comfort. They also calculated the energy consumption for the building's cooling/heating [28]. Lee developed an energy-efficient sensor network for thermal comfort measurement. A distributed sensing model was experimentally verified in terms of wireless data communication and wireless power transmission [29]. Wang et al. developed a thermistor and a polyimide-film relative humidity $(\mathrm{RH})$ sensor for global temperature and relative humidity measurement. They used the IEEE1451.2 standard for smart transducer interface module for the online monitoring of temperature and humidity in determining thermal comfort [30]. Castilla et al. presented a predictive control system to simultaneously maintain thermal comfort and indoor air quality [31]. Duan et al. presented a device for controlling the inside temperature based on fuzzy algorithms [32]. Donaisky et al. presented a PMV-based algorithm for overprotective thermal comfort of nursery plants [33]. Liang et al. proposed a thermal comfort controller for HVAC application and validated it through a simulation model [34].

However, present systems for measurement of thermal comfort suffer from numerous disadvantages, thus modifications are persistently recommended. The PMV module agrees well with high-quality field studies in airconditioned buildings in cold and warm climates. The PMV model is also limited to groups of subjects who have been exposed to an air-conditioned environment for a long time. In the case of the PMV model, we have to presume the clothing and activity levels because of the complex calculation procedure related to these variables. PMV methods also ignore air quality ( $\mathrm{CO}$ and $\mathrm{CO}_{2}$ levels) present in the indoor environment. This drawback in PMV models provides a window for errors to be introduced into its overall estimation. In the case of naturally ventilated buildings, occupants are actively adjusting to a changing outdoor environment. They also have a range of adaptive opportunity available to control the indoor environment and personal discomfort. As the occupants of naturally ventilated buildings have better control on the indoor environment (to some extent), they feel less irritated, thus increases the range of comfort parameters. In the case of the adaptive comfort model, the clothing value, activity level, and air quality automatically get included in the estimation procedure. The adaptive comfort module also provides the much needed degree of freedom to the occupants related to behavioral, psychological, and physiological adaption. Therefore, in most of the cases where the PMV model is applied to naturally ventilated buildings, it either overestimates or underestimates the prevailing comfort level in the built environment because of the above-mentioned reasons. The literature also shows that despite some interesting solutions, only a few are implemented and tested in the realworld environment, hence establishing the existence of a gap between the theory and real-world application at a scientifically accepted level.

In this article, we propose a wireless sensor network (WSN)-based comfort measurement technique, and based on this proposed technique, a Smart Comfort Sensing (SCS) System has been developed. The developed system measures thermal and indoor air comforts in real time for naturally ventilated buildings. In the development of the SCS system, we have followed the international standards such as ASHRAE55-2013, ISO7730 and IEEE1451. The SCS system is low cost and energy efficient.

\section{SYSTEM OVERVIEW}

The SCS system has been developed based on the IEEE1451 standard. The IEEE1451 standard-based application was reported in [35]-[44]. The system has been designed to monitor and control the thermal comfort and indoor air comfort parameters such as humidity, temperature, $\mathrm{CO}$, and $\mathrm{CO}_{2}$ in real time. It automatically analyzes the thermal comfort and indoor air comfort levels. The values of the thermal comfort and indoor air comfort parameters can be displayed on the GUI PC and can also be saved in a multimedia card (MMC) according to the transducer electronic data sheet. The developed system can be used in many applications such as air conditioning systems, homes, feedback control in automobiles, hospitals, and so on. The block diagram and photograph of the developed SCS system are shown in Figs. 1 and 2, respectively.

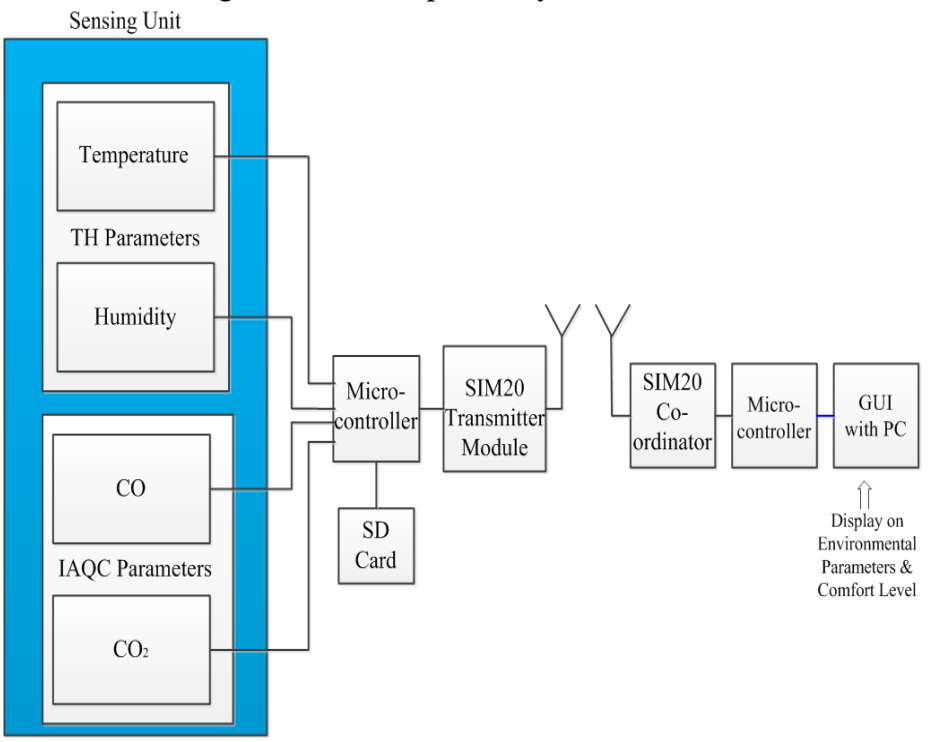

Fig. 1 Block diagram of the developed smart comfort sensing system.

\section{SENSOR NODE}

The real-time monitoring and control of the comfort sensing system were based on a WSN. The sensor node has been designed according to the IEEE1451.2 standard. The developed SCS system is consisted of a sensor node and a sink 
node. The sensor node also is consisted of a sensor array with a signal-processing circuit, Simcom SIM20, central processing unit, and SD card data storage module. The photograph of the developed sensor node is shown in Fig. 3.

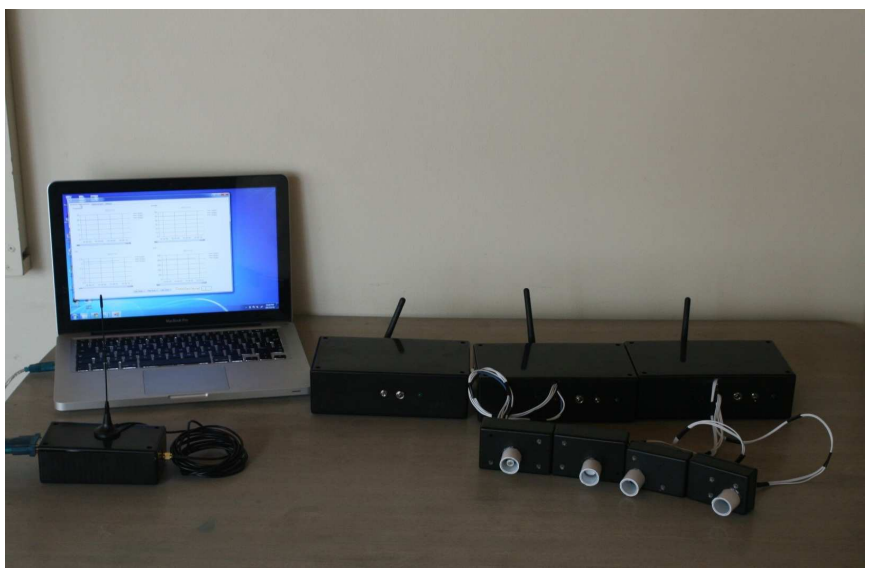

Fig. 2. Hardware of the smart comfort sensing system.

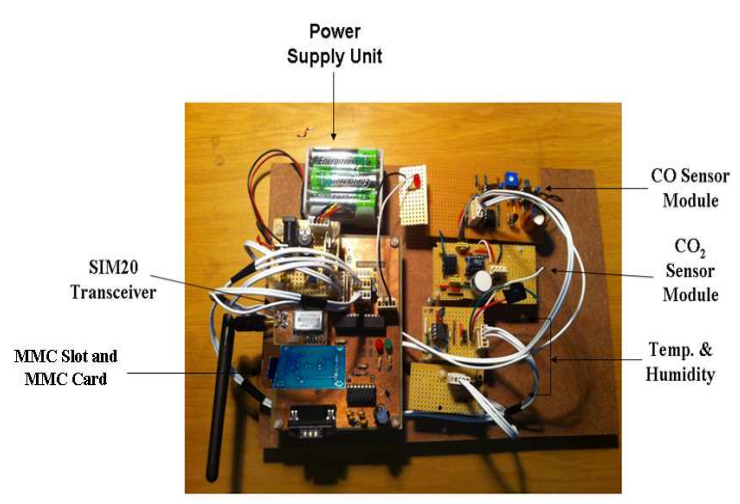

Fig. 3. Developed sensor node.

\section{A. Sensor Array}

The sensor array is consisted of a group of sensors such as temperature sensor, humidity sensor, carbon monoxide sensor, and carbon dioxide sensor. The specifications of the sensor used in the comfort sensing system are given in [45]. In the development of the sensor array, electrochemical and semiconductor sensors were used. These selected sensors have several advantages such as high accuracy, low power consumption, linearity, low hysteresis error, low cost, low radio frequency interference (RFI) and electromagnetic interference (EMI) noises, low environmental sensitivity, and high response time. The advantages, disadvantages, and comparisons of the technology of the gas sensor were reported in [46]-[51].

\section{1) Electrochemical Sensor}

The signal processing circuit of the electrochemical sensors was based on a potentiostatic circuit. In the design of the potentiostatic circuit, we have used an ultra-low input bias current amplifier and precision amplifier, that is, LMP7721,
OP90, and OP296, thereby preventing a negative impact on the sensor sensitivity, accuracy, and hysteresis of the sensor. As the voltages supplied by the sensor output were too small, the values were needed to be amplified. The sensor must not be measured with low impedance circuitry. The low cost and high accuracy instrumentation amplifier such as AD620 was used to amplify the voltage. The signal conditioning circuit, control of cross sensitivity, techniques of interfering gases, drawback and reducing the RFI/EMI noise techniques of the $\mathrm{CO}_{2}-\mathrm{D}_{1}$ sensor were reported in [45]-[48]. For the microcontroller to be able to read a full range of the readings, a voltage divider was used to divide the output voltage by two. As the virtual ground is at $2.5 \mathrm{~V}$, the microcontroller can calculate the $V_{\mathrm{CO}_{2}}$ voltage by using the following equation (1).

$V_{C O 2}=2.5-\frac{V_{A D C_{-} \mathrm{CO}_{2}} \times 2}{50}$

In the development of $\mathrm{CO}_{2}$ sensor module, the gain was fixed at 49.91. The response time and power consumption of the developed sensor module were observed to be $5 \mathrm{~min}$ and $1.1434 \mathrm{~mW}$, respectively.

\section{2) Semiconductor Sensor}

The semiconductor sensor had a good sensitivity to changes in $\mathrm{CO}$ gas concentration. The resistance of the sensor decreased as CO increased. The sensor also has a built-in heater, which was used to heat the gas to the specific temperature required for the measurement. The sensor was connected to a $5 \mathrm{~V}$ supply. The power consumption of the $\mathrm{CO}$ semiconductor gas sensor is dependent only on heater power consumption. The average heater power consumption was observed to be $14 \mathrm{~mW}$. The voltage over the load resistance was measured so as to calculate the concentration of $\mathrm{CO}$ gas. The CO solid-state sensor signal conditioning circuit was reported in [49].

\section{a) Software Design}

The TGS2442 uses three pins on the microcontroller: the first pin controls the sensor's heater, the second pin controls the sensor ON/OFF condition, and the third is connected to the analog-to-digital convertor (ADC) to measure the sensor output voltage. When the first pin was driven high, the heater was activated. When the second pin was pulled low, the sensor was enabled. To minimize the power consumption of the sensor, a heating cycle was used to prevent the heater from unnecessary consumption of power. The timing diagram was adapted from the TGS2442 application note [49]. During enabled heater pins (14 ms), the sensitivity characteristics and surface temperature of the sensing element showed that the signal detection point of the $\mathrm{CO}$ sensor was approximately $997.5 \mathrm{~ms}$. In this article, the signal point detection is $988.5 \mathrm{~ms}$ because we have obtained the optimum combination of gas sensitivity performance and minimum ambient humidity effect at around $988.5 \mathrm{~ms}$. The sensor voltage was measured every second. After five seconds, the average of the measurements was taken, and the result was transmitted to the sink node. The integrated analog signals were fed to the ADC inputs of the microcontroller. 


\section{B. Calibration of the Sensor}

The temperature sensor was calibrated using the MTD82 multimeter with a thermocouple. In addition, the humidity sensor was calibrated using the EM5510 multimeter with a built-in relative humidity sensor. The HIH-4000 ADC value was given a digital offset of $0.15 \mathrm{~V}$ so as to calibrate the sensor to the EM5510 sensor.

The electrochemical and semiconductor gas sensors calibration procedures were reported in [47], [50], and we have followed the same procedures to calibrate the gas sensor array. Firstly, the standby voltage of the developed sensor modules was defined. Pure nitrogen and clean air were used to find the standby voltage. Then, a different, known gas concentration was applied, and the resultant difference or linearization error may be corrected through signal conditioning circuits. Fig. 4 represents the calibration curve of $\mathrm{CO}$ semiconductor and $\mathrm{CO}_{2}$ electrochemical gas sensors.

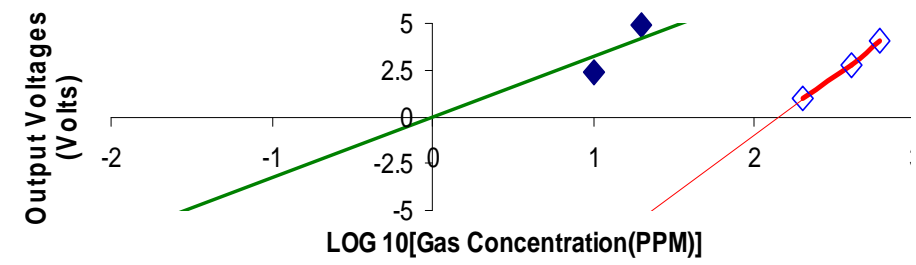

$\bullet \mathrm{CO} \prec \mathrm{CO} 2 \longleftarrow$ Linear $(\mathrm{CO}) \longleftarrow$ Linear (CO2)

Fig. 4. Calibration curve after integration of gas sensor module.

\section{Microcontroller}

Several controllers such as Raspberry Pi, Waspmotes, digital signal processors (DSPs), and microcontroller units (MCUs) were considered for use in the sensor node, but it was decided that an MCU would be used instead. An MCU consumes low power, and as there is little processing that has to be done on the node itself, the MCU has adequate processing power. Commercial sensor nodes such as the Waspmote would be easy to implement, but the high cost eliminated it as a choice. It was decided to use an ATMega88 microcontroller to control the sensor nodes. The ATMega8 8 is an 8-bit microcontroller that comes in a 32-pin package. The device has a sufficient number of ADC channels to measure the voltage supplied by each sensor. It also supports the universal asynchronous receiver transmitter (UART) and the serial peripheral interface (SPI) protocols, which can be used to communicate with most transceivers. The advantage, disadvantage, and specification of the microcontroller were reported in [52].

\section{WIRELESS COMMUNICATION}

The Simcom SIM20 was used as a transceiver in the development of the SCS system. The SIM20 specification is available in [53]. This device transmits and receives data on the $434 \mathrm{MHz}$ band but is operated by using serial communication through an UART. The device is controlled through a modified AT command set. It supports power saving modes and has a built-in mesh networking support. The WSN was implemented in a star topology. All the sensor nodes communicate directly with the sink node. As the sensors are situated relatively close to each other, power efficiency would be increased if the sensor nodes do not have to continuously communicate with each other. Fig. 5 shows the WSN diagram. Three sensor nodes communicate with the sink node, which is connected to a PC that runs the user interface program. The transmission range of the SIM20 transceiver is shown in Fig. 6. The antenna frequency ranged from $433 \mathrm{MHz}$ to 434.79 $\mathrm{MHz}$, and impedance matching had to be done to match a 50 $\Omega$ antenna on the SIM20 module. The sensor node was connected to a $50 \mathrm{~W}$ omnidirectional antenna with a gain greater than $1 \mathrm{dBi}$. The sink node was connected to a $60 \mathrm{~W}$ omnidirectional antenna with a gain of $2 \mathrm{dBi}$. The specification of the antenna was reported in [53].

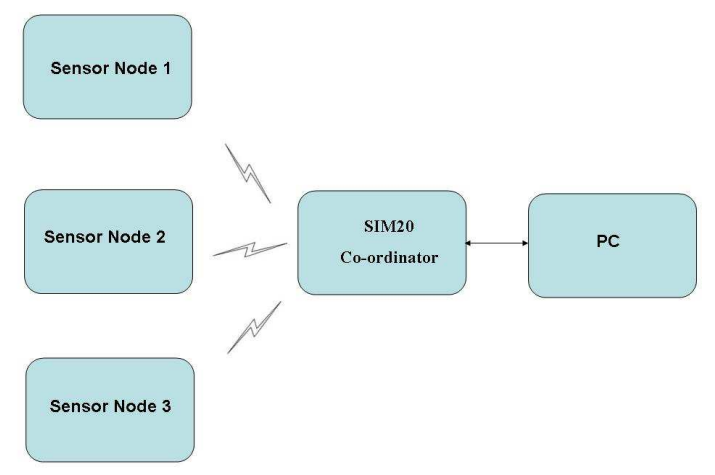

Fig. 5. The wireless sensor network diagram.

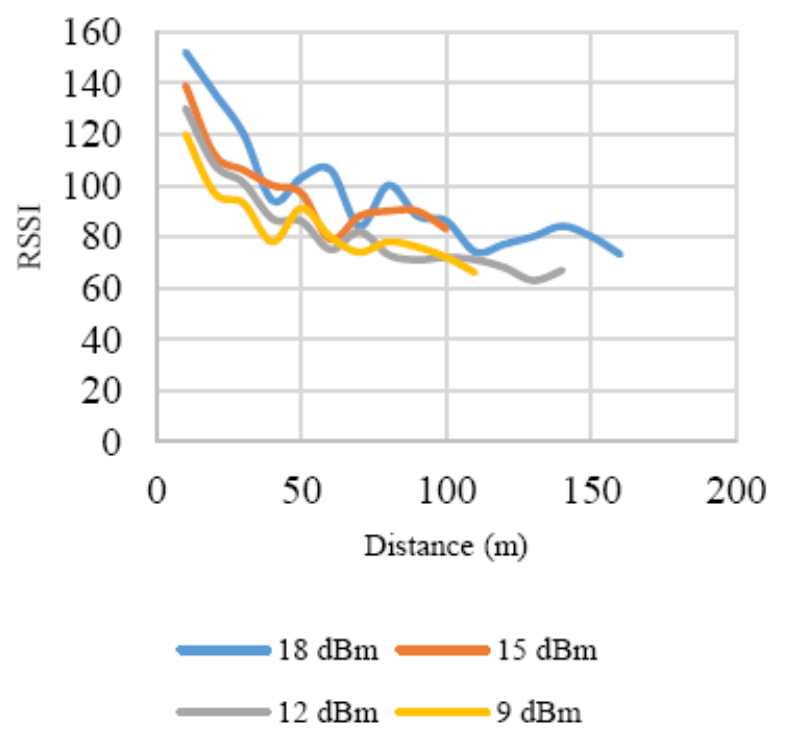

Fig. 6. Transmission range of SIM20 transceiver.

The maximum transmission distance was $60 \mathrm{~m}$ when the sensor node and the sink node were separated by six concrete walls. The SIM20 wireless transceiver that was used functioned particularly well. When the data were sent at a low bit rate, with a high transmission power on the $434 \mathrm{MHz}$ frequency, the transmission range was excellent. A maximum line of sight range of $160 \mathrm{~m}$ was achieved. To optimize the battery life of the node, the maximum transmission power must not be used if the nodes are situated close to each other. 
The sink node was able to receive data from three sensor nodes with negligible error. The sensor nodes transmitted the data at one transmission per second. Although the transceiver's air data rate can be set to 115,200 bps, the effective data rate achieved was only 17,072 bps. The use of the AT command protocol added time delays when sending multiple data messages. As only a maximum of 64 bytes per second can be transmitted, the data rate was sufficient.

\section{SINK NODE}

The sink node is the central point that allows the sensor nodes to communicate with the PC. The proposed sink node consisted of a microcontroller and a transceiver that can be connected to a PC via USB. The only function of the microprocessor is to allow the transceiver to communicate with the PC. The SIM20 transceivers are capable of communicating with an UART. The UART supports the 115,200 bps by default, and the microcontroller ATMega88 supports the low power consumption and the low cost USB 2.0 interface.

\section{A. Graphical User Interface (GUI)}

The Microsoft Visual Studio 2013 preview was used to create the GUI program in C\#. The GUI program utilized the serial port on the PC to communicate with the sink node. The sensor measurements obtained from the sink node were displayed on charts and saved in a comma-separated value format.

The purpose of the GUI is to allow the user to monitor the measured parameters of the three nodes. The data were saved to allow the user to retrieve it at a later stage. It also served to display the graphical wave form of the monitored parameters and comfort level. In the real-time measurements tab, four charts displayed the measured values versus time as they were received by the sensor nodes. The charts were auto scaled each time data were received to ensure that the current value was in the middle of the chart. If the user only wants to see data from specific nodes, the "Hide Node" buttons can hide the nodes that the user does not want to view. The GUI of the developed system is shown in Fig. 7.

\section{COMFORT ANALYSIS}

Comfort is a communal sensory experience determining whether a human enjoys and is at ease with the surroundings. It is a cumulative sensation of visual comfort, acoustic comfort, thermal comfort, and indoor air comfort. We have considered thermal comfort and indoor air quality comfort as the most important factors for determining the human comfort level in the built environment and building sustainability.

Thermal comfort is an important parameter used in building design to create an acceptable indoor environment for the building occupants. An adaptive approach to thermal comfort estimation has been adopted in the ASHRAE55-2013 standard [10]. Some researchers have added the air quality factor (CO and $\mathrm{CO}_{2}$ ) in the ISO- and ASHRAE-based PMV calculation procedures, and in accordance with this, we have chosen the adaptive PMV calculation technique with air quality aspect [25]-[31].
The collected data of the developed system were then analyzed statistically and used to develop a corrected PMV formula using the multiple regression technique.

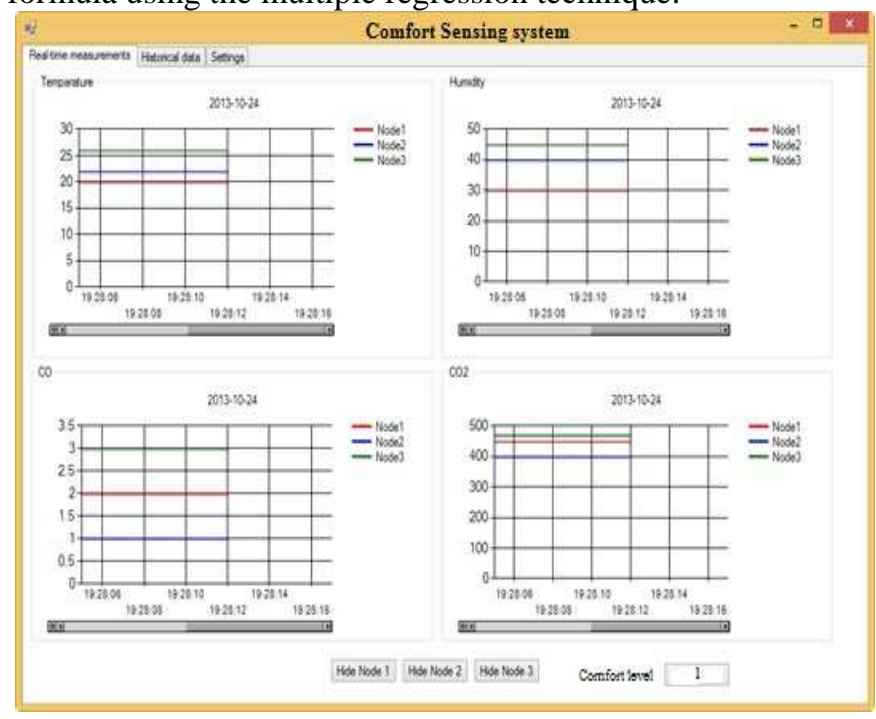

Fig. 7. The GUI of the comfort sensing system.

This formula was developed using the first one month of data and then validating the developed formula on the next month's data. During this experiment, we found that the coefficient of correlation $\left(\mathrm{R}^{2}\right)$ was greater than 0.97 . The high value of $\mathrm{R}^{2}$ suggested that this method can be used to predict the thermal environment with fair accuracy. The developed, corrected PMV formula was based on data collected through the developed SCS system:

$$
\begin{aligned}
& P M V_{\text {Corrected }}=-3.87922-0.16219 \times C_{\mathrm{CO}}-0.00166 \times \mathrm{C}_{\mathrm{CO}_{2}} \\
& -0.01604 \times R H+0.250396 \times T+0.648875 \times C L O
\end{aligned}
$$

where $C_{C O}$ is the concentration of $\mathrm{CO}(\mathrm{ppm}), C_{\mathrm{CO}_{2}}$ is the concentration of $\mathrm{CO}_{2}(\mathrm{ppm}), T$ is the air temperature $\left({ }^{0} \mathrm{C}\right), \mathrm{RH}$ is the air relative humidity (\%), and $C L O$ is the thermal resistance of clothing (clo). This approximate relation is acceptable for metabolic rate between 1.0 met to 1.3 met, clothing 0.2 to 0.5 , and air velocity up to $0.20 \mathrm{~m} / \mathrm{s}$ [9], [10]. The $P M V_{\text {corrected }}$ model is valid for the whole year in naturally ventilated buildings. The developed formula was programmed in embedded ' $\mathrm{C}$ ' and burnt into the microcontroller.

\section{EXPERIMENTAL PROCEDURE}

In this section, we present the experimental procedures followed to develop the SCS system. The methodology for data collection was based on the subjective approach, objective approach, and results from the developed SCS system. Star networks were used, and all the sensors during the experiment were placed $1.2 \mathrm{~m}$ above floor level. A set of real-time measurements data of the air gases $\left(\mathrm{CO}\right.$ and $\left.\mathrm{CO}_{2}\right)$ and environmental parameters (temperature and humidity) sensors were recorded in an ordinary laboratory environment and are shown in Fig. 8. In Fig. 8, the temperatures vary from $22^{\circ} \mathrm{C}$ to $27^{\circ} \mathrm{C}$ and represent a swing of $5^{\circ} \mathrm{C}$. It is observed that the relative humidity varies from $43 \%$ to $75 \%$. $\mathrm{CO}$ 
concentration levels vary from $6 \mathrm{ppm}$ to $9 \mathrm{ppm}$, and $\mathrm{CO}_{2}$ concentration varies from $400 \mathrm{ppm}$ to $430 \mathrm{ppm}$.

The SCS system vote versus temperature is shown in Fig. 9. The increase in temperature was achieved through a heater $(0.5 \mathrm{KV}$ for $5 \mathrm{~h})$ and recorded and displayed the SCS system vote on GUI.

The subjective approach was based on the judgment of the inhabitants on the acuity of thermal comfort in terms of acceptability and preference to colder or warmer environments. Questionnaires were used to investigate thermal comfort and indoor air quality comfort perceptions. The questionnaire was divided into three sections that dealt with general information, thermal comfort, and indoor air quality. During the survey, the respondents were asked to vote on a seven-point ASHRAE thermal sensation scale regarding their perceptions on the existing thermal environment. On the thermal sensation scale, -3 stands for cold, 0 for neutral, and +3 for hot thermal conditions. For indoor air quality assessments, subjects were provided with a scale to register their vote for acceptable and unacceptable indoor air quality. The corresponding temperature $\left({ }^{\circ} \mathrm{C}\right)$, relative humidity $(\%)$, and levels of $\mathrm{CO}$ and $\mathrm{CO}_{2}$ concentrations were also recorded together with votes. In this study, the development system was tested on 50 subjects over a period of 10 days. For each subject, measurements were taken five times. The building considered in this study was "naturally ventilated", and no restrictions were imposed on the subjects during experiments. An objective approach, defined as PMV values calculated according to the ISO7730 calculation procedure, was used. The output values of the developed SCS system were used. The data were collected at the same time. The comparative plot of the subjective approach (TSV-thermal sensation vote), objective approach (ISO7730-based PMV), and SCS system vote are shown in Fig. 10. Results show that the output values from the SCS system are in good agreement with the comfort sensing vote of a human being. The ISO7730-based PMV calculation was different from the ASHRAE- and SCS-based PMV, and the difference was mainly caused by the adaptive nature of inhabitants. It raised the question of whether a modification in the ISO7730 standard is required. This means that the air quality $\left(\mathrm{CO}\right.$ and $\left.\mathrm{CO}_{2}\right)$ factors could be added to the ISO7730 standard-based PMV calculation procedure.

We considered these pollutant gases because they had direct influence on the health of the occupants in the built environment. Indoor air quality comfort parameters such as $\mathrm{CO}$ and $\mathrm{CO}_{2}$ were measured in real time, and their concentration limit in built environment were also controlled. Healthy people can tolerate $\mathrm{CO}_{2}$ level of up to $10,000 \mathrm{ppm}$ without serious health effects, but the level of $\mathrm{CO}_{2}$ should always be kept below 1,000 ppm. Regarding the concentration of CO: healthy people can tolerate $\mathrm{CO}$ level of up to $10 \mathrm{ppm}$ without serious health effects, but it should always be kept below 6 ppm [54], [55]. The upper level of $\mathrm{CO}$ and $\mathrm{CO}_{2}$ gas concentrations were fixed at $4 \mathrm{ppm}$ and $500 \mathrm{ppm}$, respectively, for the developed SCS system. The output of each sensor, thermal comfort, and indoor air quality comfort indices were displayed on the GUI PC. If an increase in the concentration level of indoor air comfort parameters and thermal comfort parameters are observed, then a signal is transmitted through a SIM20 transmitter module to the sink node; the sink node was programmed to control the comfort indices of appliances such as exhaust fan, air conditioning, etc.

\section{RESULTS AND DISCUSSION}

In this article, we present a low-cost and energy-efficient prototype of an SCS system. The prototype system is consisted of the GUI and communication, sensor node, and sink node modules. These modules were successfully developed based on the ASHRAE55-2013, ISO7730, and IEEE1451 standards. This prototype system was tested for the real-time monitoring of thermal comfort and indoor air quality comfort parameters and is also capable of automatically analyzing and displaying the output of the thermal comfort level. The sensors were calibrated after integration through the static chamber method, firstly by defining the standby voltage of the developed sensor module, and after that by applying a different known gas concentration. The resulting differences or linearization error were corrected through the signal processing circuit. If system calibration is required in future, it can be adjusted again through this procedure.

We used two types of gas sensors during the development of the SCS system: one is the semiconductor gas sensor, and the other the electrochemical gas sensor. We observed that the electrochemical sensor has a low power consumption compared with the semiconductor sensor. The EMI (electromagnetic interference) and RFI (radio frequency interference) noises in electrochemical sensor were successfully improved. The power consumption of the multimedia card depends on the data transfer speed (clock rate). In the SPI (serial peripheral interface) mode, we used the $20 \mathrm{MHz}$ crystal. $\mathrm{F}_{\mathrm{OSC}} / 16$ bit rate or clock rate was used in the microcontroller. Then, $\frac{F_{o s c}}{16}=\frac{20 M H z}{16}=1.25 \mathrm{MHz}$. The maximum clock frequency of the developed system was fixed at $1.25 \mathrm{MHz}$. The typical range of the MMC card is $66 \mathrm{~mW}$ at a clock frequency $25 \mathrm{MHz}$; but in our case, we used a clock frequency of $1.25 \mathrm{MHz}$. According to the clock frequency, the MMC consumed a maximum power of $16.5 \mathrm{~mW}$. The maximum power consumption of the sensor node with the sensor array and MMC attached in the node was found to be $60 \mathrm{~mW}$ (at which data was transmitted). In the trial of the developed SCS system, we used a Li-ion battery rated at 11.1 $\mathrm{V}$ (350 mAh). The developed SCS system worked up to approximately $60 \mathrm{~h}$, and the power consumption of the developed system was lesser than the other available systems.

\section{CONCLUSION}

In this article, we present a low-cost and energy-efficient prototype of a smart comfort sensing (SCS) system. The prototype system is consisted of the GUI and the communication, sensor node, and sink node modules. These modules were successfully developed based on the IEEE1451 standard. This prototype system was tested for the real-time monitoring of thermal and air quality comforts in situ according to ASHRAE55-2013 and ISO7730 standards. Experimental results in a simulated environment clearly suggested that the developed thermal comfort smart sensing system can be utilized in an air conditioning system as a practical means of monitoring thermal comfort and feedback 
control of homes, automobiles, hospitals, etc. The maximum power at which data is transmitted was found to be $60 \mathrm{~mW}$. The power consumption and cost of the developed SCS system are lesser than the existing systems. In addition, the performance and quality of measurements of the developed system are better compared with the existing systems.
In further research, we will focus on the potential alternative communication technology (such as DASH 7), which allows better signal propagation (penetration) through walls, windows, doors, etc. Moreover, this system will be explored for the control of the thermal comfort controlling parameter through home appliances (heater, air conditioning, exhaust fans, etc.).
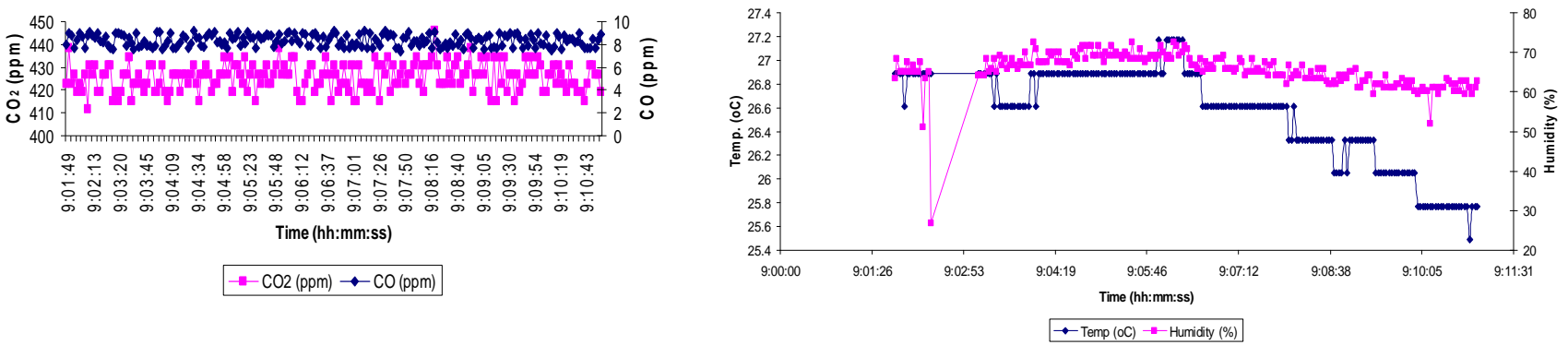

Fig. 8. Real-time monitoring of indoor gases $\left(\mathrm{CO}\right.$, and $\left.\mathrm{CO}_{2}\right)$ and environmental parameters.

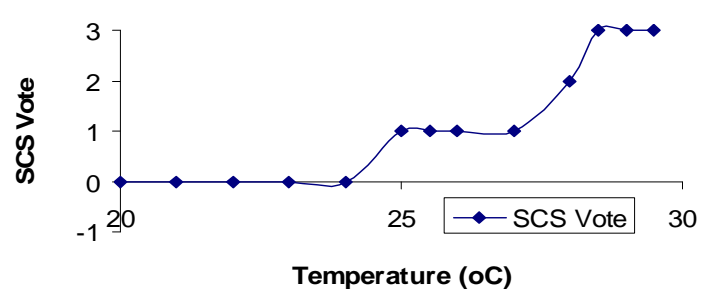

Fig. 9. Real-time capture of SCS vote vs temperature

(0.5 KV heaters on $5 \mathrm{~h})$.

\section{REFERENCES}

[1] T. A. Nguyen and M. Aiello, "Energy intelligent buildings based on user activity: A survey," Energy and Buildings, vol. 56, pp. 244-257, 2013.

[2] J. Y. Hong, E. H. Suh, and S. J. kim, "Context aware systems: a literature review and classification," Expert Systems with Applications, vol. 36, pp. 8509-8522, 2009.

[3] K. Whitehouse, J. Ranjan, J. Lu, T. Sooker, M. Saadat, A. Canfora, H. H. Hossein, G. Staengl, and C. M. Burke, "Towards occupancy driven heating and cooling," pp. 17-25, July/Aug. 2012. DOI: 10.1109/MDT.2012.2201439.

[4] B. A. Serrano and M. V. Reyes, "Nonlinear control of a heating ventilating and air conditioning system with thermal load estimation," IEEE Trans. Control Systems Tech., vol. 7, no. 1, pp. 56 - 63, Jan 1999.

[5] G. W. Brundrett, "Controlling the built environment," Electronics and Power, pp. 248-251, April 1974.

[6] L. J. Hollander, "Discussion of economics of thermal environment control," IEEE Trans. Industry and General Applications, pp. 234-238, March/April 1968.

[7] M. K. singh, S. Mahapatra, and S. K. Atreya, "Adaptive thermal comfort model for different climatic zones of north east India," Applied Energy, vol. 88, pp. 2420-2428, 2011.

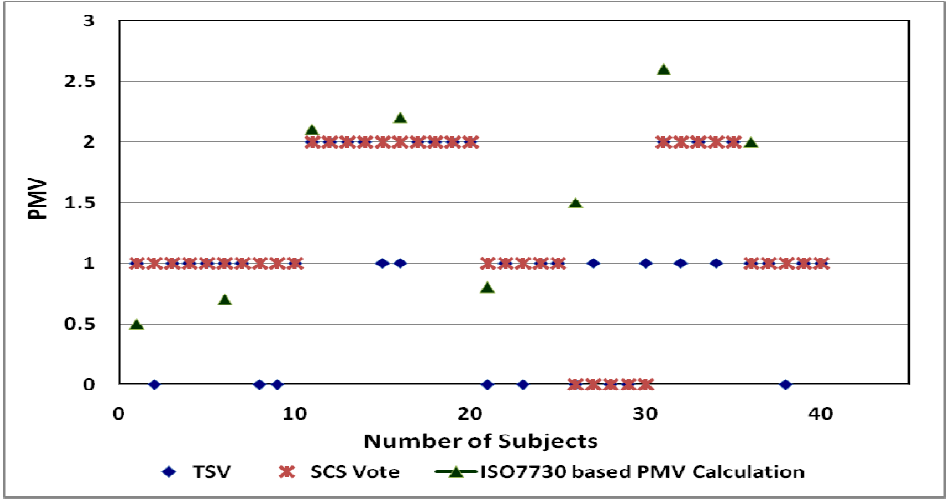

Fig. 10. Comparative study of PMV.

[8] J. Kang and S. Park, "Integratedcomfort sensing system on indoor climate," Sensors and Actuators, vol. 82, pp. 302-307, 2000.

[9] ISO. Moderate thermal environment - determination of PMV and PPD indices and specifications of the conditions for thermal comfort, ISO 7730, Geneva: International Organization for Standardization, (1994).

[10] Thermal environmental conditions for human occupancy, American Society of Heating, Refrigerating and Air-conditioning Engineers Inc., (2004) ASHRAE 55-2013.

[11] J. A. Veitch, "Psychological processes influenceing lighting quality," Journal of the Illuminating Engineering Society, v. 30, no. 1, 2001, pp. 124-140.

[12] Y. Honeywell and A. Kon, "Thermal comfort sensor," IEEE IMTC 94, 10-12 May 1994, Hamamatsu, pp. 454-456, 1994.

[13] N. Brelih, "Thermal and acoustic comfort requirements in European standards and thermal regulations," Rehva J., pp. 16-19, March 2013.

[14] C. M. Chu and T. L. Jong, "A novel direct air conditioning load control method," IEEE Trans. Power Systems, vol. 23, no. 3, pp. 1356-1363, Aug. 2008.

[15] T. G. Nikolaou, D. S. Kolokotsa, G. S. Stavrakakis, and I. D. Skias, "On the application of clustering techniques for office buildings, energy and thermal comfort classification," IEEE Trans. Smart Grid, vol. 3, no. 4, pp. 2196-2210, Dec. 2012. 
[16] F. D. Angelis, M. Boaro, D. Fuselli, S. Squartini, F. Piazza, Q. Wei, "Optimal home energy management under dynamic electrical and thermal constraints," IEEE Trans. Industrial Informatics, vol. 9, no. 3, pp. 1518-1527, Aug. 2013.

[17] W. Lassow, E. L. Lustenader, and K. F. Schoch, "A thermal model for the evaluation of subway ventilation and air conditioning," IEEE Trans. Industry Applications, vol. IA-8, no. 4, pp. 504-513, July-Aug. 1972.

[18] C. Gomez and J. Paradells, "Wireless home automation networks: a survey of architectures and technologies," IEEE Communications Magazine, pp. 92-101, June 2010.

[19] C. Chen, J. Wang, Y. Heo, and S. Kishore, "MPC based appliance scheduling for residential building energy management controller," IEEE Trans. Smart Grid, vol. 4, no. 3, pp. 1401-1410, Sep. 2013.

[20] S. Kishore and L. Snyder, "Control mechanisms for residential electricity demand in smart grids," in proc. IEEE Conf. Smar Grid Commun., 2010.

[21] P. Du and N. Lu, "Appliances commitment for household load scheduling," IEEE Trans. Smart Grid, vol. 2, no. 2, pp. 411-419, 2011.

[22] R. Mukaro and X. F. Carelse, "A microcontroller based data acquisition system for solar radiation and environment monitoring," IEEE Trans. Instrum. Meas., vol. 4, no. 6, pp. 1232-1238, 1999.

[23] W. L. Tse and W. L. Chan, "A distributed network for measurement of human thermal comfort feelings," Sensors and Actuators A: Physical, vol. 144, pp. 394-402, 2008.

[24] W. L. Tse and W. L. Chan, "Real time measurement of thermal comfort by using an open networking technology," Measurement, vol. 40, pp. 654-664, 2007.

[25] A. Kumar, I. P. Singh, and S. K. Sud, "An approach towards development of PMV based thermal comfort smart sensor," Intern. J. Smart Sensing and Intelligent Systems, vol. 3, no. 4, Dec. 2010.

[26] M. I. M. Rawi and A. A. Adnan, "Development of intelligent wireless sensor network for human comfort index measurement," Procedia Computer Science, vol. 5, pp. 232-239, 2011.

[27] R. M. Reffat and E. L. Harkness, "Environmental comfort criteria: weighting and integration," J. of Performance of Constructed Facilities, pp. 104-108, Aug. 2001

[28] S. Atthajariyakul and T. Leephakpreeda, "Real-time determination of optimal indoor air condition for thermal comfort, air quality and efficient energy usage," Energy and Buildings, vol. 36, pp. 720-733, 2004.

[29] D. Lee, "Development of light powered sensor networks for thermal comfort measurement," Sensors, vol. 8, pp. 6417-6432, 2008.

[30] Y. Wang, M. Nishikawa, R. Maeda, M. Fukunage, and K. Watanabe, "A smart thermal environment monitor based on IEEE 1451.2 standard for global networking," IEEE Trans. Instrum. Meas., vol. 54, no. 3, June 2005.

[31] M. D. M. Castilla, J. D. Alvarez, J. E. N. Rico, F. Rodriguez, and M. Berenguel, "A multivariable nonlinear MPC control strategy for thermal comfort and indoor air quality," $39^{\text {th }}$ Annual Conference of the IEEE Industrial Electronics Society, IECON 2013, 10-13 Nov. 2013, Vienna, pp. 7908-7913.

[32] C. Duan, X. Ding, F. Shi, X. Xiao, and P. Duan, "PMV-based fuzzy algorithms for controlling indoor temperature," $\sigma^{\text {th }}$ IEEE Conference on Industrial Electronics and Applications, 2011, pp. 1492-1496.

[33] E. Donaisky, G. H. C. Oliveira, R. Z. Freire, and N. Mendes, "PMVbased predictive algorithms for controlling thermal comfort in building plants," $16^{\text {th }}$ IEEE International Conference on Control Applications, 13 Oct. 2007, Singapore, pp. 182-187.

[34] J. Liang and R. Du, "Thermal comfort control based on neural network for HVAC application," Proceedings of the IEEE Conference on Control Applications, 28-31 Aug. 2005, Toronto, Canada, pp. 819-824.

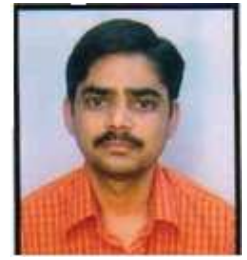

Anuj Kumar received his Ph.D. degree in Embedded Systems from the Indian Institute of Technology Delhi, India in 2011, M. Tech. degree in Instrumentation from the National Institute of Technology Kurukshetra, Haryana, India in 2004 and M. Phil in Instrumentation from the Indian Institute of Technology Roorkee, UA, India in 2000.

He was with APL Intelligent Embedded, New Delhi, India where he was involved in development of microcontroller-based applications from 20002002. In 2004, he joined DellSoft Technologies, New Delhi, India as an Instrumentation Engineer - EDA. From January 2012 to October 2102, as a post-doctoral research fellow at the Electrical and Computers Engineering Department, University of Seoul, South Korea. Since November 2012 he has
[35] K. B. Lee and R. D. Schneeman, "Distributed measurement and control based on the IEEE1451smart transducer interface standards," IEEE Trans. Instrum. Meas., vol. 49, No. 3, pp. 621-627, June 2000.

[36] D. Wobschall, "networked sensor monitoring using the universal IEEE1451 standard," IEEE Instrum. Meas. Magazine, pp. 18-22, April 2008.

[37] K. B. Lee and M. E. Reichardt, "Open standards for homeland security sensor networks," IEEE Instrum. Meas. Magazine, pp. 14-21, Dec. 2005.

[38] E. Y. Song and K. Lee, "Understanding IEEE 1451-networked smart transducer interface standard," IEEE Instrum. Meas. Magazine, pp. 1117, April 2008.

[39] M. Dunbar, "Plug and play sensors in wireless networks," IEEE Instrum. Meas. Magazine, pp. 19-23, March 2001.

[40] L. H. Eccles, "The need for smart transducers an aerospace test and evaluation perspective," IEEE Instrum. Meas. Magazine, pp. 23-28, April 2008.

[41] S. R. Roosi, A. A. Carvalho, A. C. R. Silva, E. A. Batista, C. Kitano, T. A. S. Filho, and T. A. Prado, "Open and standardized resources for smart transducer networking," IEEE Trans. Instrum. Meas., vol. 58, No. 10, pp. 3754-3760, Oct. 2009.

[42] K. C. Lee, M. H. Kim, S. Lee, and H. H. Lee, "IEEE 1451 based smart module for in-vehicle networking systems of intelligent vehicles," IEEE Trans. Instrum. Meas., vol. 51, No. 6, pp. 1150-1158, Dec. 2004.

[43] H. M. G. Ramos, J. M. D. Pereria, V. Viegas, O. Postolache, and P. M. B. S. Girao, "A virtual instrument to test smart transducer interface modules (STIMS)," IEEE Trans. Instrum. Meas., vol. 53, no. 4, pp. 1232-1239, 2004.

[44] K. B. Lee and E. Y. Song, "Object-oriented application framework for IEEE 1451.1 standard," IEEE Trans. Instrum. Meas., vol. 54, no. 4, pp. $1527-1533,2005$.

[45] A. Kumar, I. P. Singh, and S. K. Sud, "Energy efficient and low cost indoor environment monitoring system based on IEEE 1451 standards," IEEE Sensor J., vol. 11, No. 10, pp. 2598-2610, Oct. 2011.

[46] A. Kumar, H. Kim, and G. P. Hancke, "Environment Monitoring System: A Review", IEEE Sensor J., vol. 13, No. 4, pp. 1329-1339, April 2013.

[47] A. Kumar and G. P. Hancke, "Energy efficient environment monitoring system based on the IEEE 802.15.4 standard for low cost requirements", IEEE Sensor J., vol. 14, no. 8, pp. 2557-2566, Aug. 2014.

[48] Alphasense, "AAN 401 introduction to CO2-D1 - solid state sensor for CO2," 2013.

[49] Figaro, TGS2442, "Technical Information for Carbon Monoxide Sensors," pp. 1-14, 2007.

[50] N. Kularatna and B. H. Sudantha, "An environmental air pollution monitoring system based on the IEEE 1451 standard for low cost requirements," IEEE Sensors J., vol. 8, no. 4, pp. 415-422, 2008.

[51] J. W Gardner, P. k. Guha, F. Udrea, and J. A. Covington, "CMOS interfacing for integrated gas sensors: a Review," IEEE Sensors Journal, vol. 10, no. 12, pp. 1833-1848, 2010.

[52] http://www.atmel.com/Images/doc8161.pdf. (visited on date: March 2013)

[53] Simcom, "SIM20_HD_V2.02 hardware design," 2009.

[54] http://www.treehugger.com/natural-sciences/indoor-air-quality-causesof-testing-and-monitoring-indoor-air-pollution.html (Visited on date: Nov 12, 2006).

[55] P. M. Bluyssen, "The indoor environment handbook," RIBA Publishing, USA, 2009, ISBN: 978-1-84407-787-8.

been Vice-Chancellor Post Doctoral Fellow at the Department of Electrical, Electronic and Computer Engineering of the University of Pretoria, South Africa. His research interests include smart sensing systems, intelligent systems, microcontroller-based applications, and instrumentation electronics.

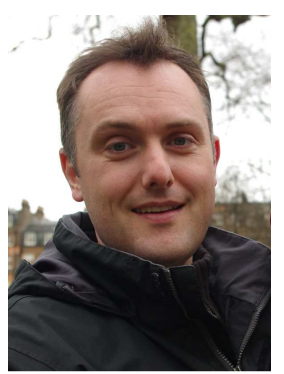

Gerhard P. Hancke is an Assistant Professor in the Department of Computer Science at City University of Hong Kong. He obtained B.Eng. and M. Eng. degrees from the University of Pretoria (South Africa) and a $\mathrm{PhD}$ in Computer Science from the University of Cambridge in 2008. He is interested in sensing systems for industrial applications. 